\title{
EL CINE DESDE LA PERSPECTIVA DE LA CIENCIA POLÍTICA
}

\section{Manuel Trenzado Romero}

Universidad de Granada

\begin{abstract}
RESUMEN
La cultura de masas es probablemente uno de los fenómenos peculiares más importantes del siglo XX que menos atención han recibido desde la perspectiva de la Ciencia Política. En este artículo indagamos en primer lugar en los motivos que han podido motivar este desinterés politológico por la cultura de masas en general y, en particular, por el cine, uno de sus más claros exponentes. En el epígrafe segundo damos cuenta de la manera en que la disciplina de la Comunicación Política, yendo más allá del paradigma dominante de la persuasión del votante, se ha ido abriendo en los últimos años al estudio de los discursos basados en la ficción y en el entretenimiento, centrándonos sobre todo en una revisión de la literatura anglosajona sobre estos temas. En el último epígrafe hacemos un breve análisis del uso del cine por algunos movimientos sociales en cuanto arma y lugar de contestación política, centrándonos básicamente en las relaciones entre socialismo, feminismo y cine. Consideramos que el estudio politológico de los discursos públicos con los que se recrean las identidades colectivas y se construyen los universos políticos de la ciudadanía son un campo de estudio productivo. La creciente expansión de los enfoques de la teoría del discurso y de los Estudios Culturales en Ciencia Política parecen confirmar esta apertura académica.
\end{abstract}

El cine, como institución social, y las películas, como objetos comunicativos concretos, arrastran desde sus primeros tiempos un estigma de ilegitimidad cultural y científica ${ }^{1}$. Sin embargo, esta consideración del cine como algo exó-

1 Agradezco las sugerencias de los evaluadores de la REIS, buena parte de las cuales han sido recogidas en el texto. 
tico o poco serio no es obstáculo para que diversas ciencias sociales se interesen por el cine como fenómeno sociopolítico. Cuando profundizamos en el interés por el cine de la Sociología, la Historia, la Psicología o la Antropología, se presenta ante nosotros un campo fecundo y rebosante de investigaciones; campo que forma parte ya de la misma historia de estas disciplinas. Por este motivo, nos interesa dilucidar a continuación cómo el cine - en cuanto fenómeno sociopolítico- es y puede ser objeto de estudio de la Ciencia Política. Veremos para ello, en primer lugar, las razones concretas que han motivado que el estigma de ilegitimidad del cine se haya traducido en el ámbito de la Ciencia Política en un desinterés mayor que en otras ciencias sociales cercanas. En segundo lugar, veremos de qué manera el cine, lejos de ser un mero capricho de politólogos cinéfilos, se ha introducido en la Ciencia Política a través de la ampliación del ámbito de estudio de la Comunicación Política hacia la cultura popular y de masas. Para ello se hace necesario distinguir las principales corrientes en Comunicación Política que se interesan por el tópico «cine y política», así como sus presupuestos teóricos. Finalizaremos, analizando brevemente la manera en que algunos movimientos orientados hacia la praxis política (socialismo y feminismo) han integrado al cine en sus estrategias teóricas y prácticas.

\section{EL DESINTERÉS DE LA CIENCIA POLÍTICA POR EL CINE}

La premisa necesaria para poder comenzar a hablar del cine desde una perspectiva politológica es convenir que existe una relación entre cine y política. Esto, que en principio no parece ofrecer muchas dificultades (todos podemos recordar alguna película de tema político o algún ejemplo de censura), se convierte en un resbaladizo terreno para la reflexión teórica. Es más, como ha puesto de manifiesto Zimmer, durante mucho tiempo la vinculación de los términos «cine» y "política» constituyó un escándalo: "[Esta vinculación] estaba prohibida por un tabú, compartido por quienes hacían las películas, quienes las consumían y quienes hablaban de ellas. ¿De dónde procedía este tabú? Como ocurre siempre, de una religión, la religión del espectáculo»².

Sólo muy poco a poco, las ciencias sociales —en especial la Antropología, la Psicología y la Sociología - tomaron como objeto de estudio a un fenómeno que desbordaba la vida cotidiana y que era uno de los más claros indicios de los profundos cambios del siglo XX (otro índice de modernidad minusvalorado por las ciencias sociales, coetáneo al cine, y que no podemos abordar aquí es el fútbol). En este mismo sentido, la Ciencia Política se ha interesado por el cine sólo de forma excepcional y extremadamente marginal, con mucha menos

2 Christian Zimmer, Cine y política, Salamanca, Sígueme, 1975, p. 14. Algunas de las ideas de Zimmer son deudoras de Guy Debord y su famosa crítica situacionista La sociedad del espectáculo. 
frecuencia e intensidad que otras ciencias sociales. Podemos señalar, al menos, tres causas que pueden explicar este desinterés:

1. El tradicional peso del institucionalismo en Ciencia Política. A la hora de trazar los límites académicos de la disciplina, la politología ha defendido un núcleo duro de objetos y métodos de conocimiento que definen lo qué es y de qué debe ocuparse la Ciencia Política (partidos, elecciones, comportamiento político, sistemas políticos, etc.). Esta concepción institucionalista de lo público provoca que las experiencias de los individuos no definidas por su relación específica con las instituciones políticas que son el objeto de estudio tiendan a ser ignoradas. Este es el caso del pequeño subgénero de investigación en comunicación política llamado "política y cine» ${ }^{3}$.

2. Consideración de la ficción como algo ajeno a la realidad política. Según el enfoque behavioralista tradicionalmente dominante en la Ciencia Política, la política en cuanto práctica social tiene como último fundamento el poder y las relaciones en torno a él. Por ello, el cine como práctica discursiva y significante formaría parte, en todo caso, del ámbito cultural e imaginario. Más aún, dado su carácter eminentemente espectacular, de ficción y entretenimiento, su incidencia política e ideológica en la conducta — se presupone- es muy reducida. A mayor abundamiento, los estudios científicos tradicionales sobre los efectos de la ficción en la socialización política o en la cultura política de los individuos han puesto de relieve la casi insuperable carencia de una metodología eficaz y rigurosa para poder abordar estos temas. Por este motivo, una vez admitida la importancia de la comunicación pública para entender la política actual, rara vez se da el paso más allá del género informativo (noticias, debates, opinión pública).

3. Una última causa que puede explicar el desdén de la Ciencia Política por el cine es la apropiación del tópico "cine y política» por parte de teóricos a menudo ajenos a la disciplina (vgr. crítica cinematográfica estructuralista, análisis semióticos, cineastas militantes, etc.). Por este motivo, la Ciencia Política más tradicional ha observado estos problemas como algo interesante pero ajeno, perteneciente a otros paradigmas científicos y a la crítica cultural radical.

A pesar de todos estos obstáculos citados, en los últimos años se está produciendo una incorporación de la investigación fílmica en ámbitos politológicos, localizada fundamentalmente en Estados Unidos. La vía seguida para ello ha sido la ampliación del objeto de estudio de la Comunicación Política hacia campos tradicionalmente periféricos a ella, como podrían ser la cultura de masas y el entretenimiento. Nicholas Garnham — siempre polémico desde su

3 Vid. Robert L. SaVage, "The Stuff of Politics through Cinematic Imagery: An Eiconic Perspective», en R. L. Savage y Dan Nimmo (eds.): Politics in Familiar Contexts, Norwood, Ablex, 1990, pp. 120-121. 
postura crítica - atribuye esta reciente absorción y legitimación académica del cine a la pérdida de su lugar central como medio de comunicación y a su correlativa inocuidad política. Para el autor británico el cine se ha convertido en un objeto disponible para su estudio precisamente cuando por su extensión ha dejado de ser un medio centralmente importante en la producción y distribución de la cultura de masas. En contraste la televisión, la radio o la prensa son lugares para la confrontación política e ideológica y, por tanto, no pueden ser tratados como objetos de estudio de la misma manera ${ }^{4}$.

Desde nuestra perspectiva no podemos estar de acuerdo con Garnham; y ello por varios motivos. En primer lugar, en un nivel teórico porque consideramos que las películas, en cuanto discursos públicos de la comunicación de masas insertos en el nuevo espacio público, constituyen un lugar de propuesta de representaciones culturales e imaginarios sociales, que conforman en última instancia la realidad cotidiana y la memoria colectiva. Como indican Ryan y Kellner, refiriéndose al cine en cuanto espacio discursivo de lucha simbólica, el tipo de representaciones que prevalecen en una cultura es un asunto político crucial: "las representaciones culturales no sólo dan forma a las disposiciones psicológicas sino que también juegan un importante papel a la hora de determinar qué realidad social se construirá; esto es, qué figuras y contornos prevalecerán en el proceso de modelación de la vida e instituciones sociales ${ }^{5} »$.

Desde esta perspectiva, el cine no sería — como afirma Garnham- diferente como lugar de conflicto político e ideológico a la televisión y a los otros medios. Si bien es cierto que el cine ha perdido su papel hegemónico en la producción de cultura de masas (al menos en los países desarrollados), no es menos cierto que puede hablarse de la existencia de una cultura mass-mediada en la que el cine está muy presente. En ésta, los tradicionales medios de comunicación no compiten entre sí sino que forman parte del mismo entramado financiero, comercial, ideológico, etc.

El segundo motivo por el que discrepamos con la idea de Garnham de que el cine ha adquirido su status científico paralelamente a la pérdida de su virtualidad política, es de orden académico. Como veremos a continuación, la expansión del campo de los estudios en Comunicación Política afecta no sólo al cine sino también a los demás medios (incluyendo a la novela y a la pintura) en cuanto generadores/exponentes de la cultura de masas. Es la incorporación del estudio político de lo imaginario lo que ha hecho recipiendarios en la academia a estos media, y no precisamente su inocuidad política.

${ }^{4}$ Nicholas Garnham, «Film and Media Studies: Reconstructing the Subjet», en Philip Schlesinger y Colin Sparks (eds.): Culture and Power, Londres, Sage, 1992, p. 57.

5 Michael Ryan y Douglas Kellner, Camera Politica. The Politics and Ideology of Contemporary Hollywood Film, Bloomington, Indiana University Press, 1988, p. 13. 


\section{EL INGRESO DEL CINE EN LA COMUNICACIÓN POLÍTICA}

Pese a que el cine había sido objeto de atención politológica desde hacía muchas décadas, este interés era puntual y no obedecía a ningún enfoque metodológico específico (salvo las aproximaciones marxistas ya aludidas) ${ }^{6}$. La aparición de un marco de investigación más adecuado ha venido dado por el inevitable interés de la Ciencia Política por la comunicación pública y los media, a remolque de las aportaciones de los estudios de Opinión Pública, la Communication Research y la Teoría del Discurso. No pensemos que la comunicación de masas ha atraído siempre la atención de la Ciencia Política. De hecho el interés sistemático por este tópico es relativamente reciente. Si ojeamos la ya clásica enciclopedia de Greenstein y Polsby, Handbook of Political Science (1975), podemos ver que en sus ocho volúmenes sólo hay una referencia superficial a la comunicación de masas (y para indicar tópicamente que los mass media refuerzan las actitudes más que cambiarlas: una afirmación que contaba por entonces con más de treinta años de consenso en la Communication Research). Sin embargo, desde la fecha de publicación del Handbook de Greenstein y Polsby —e incluso desde unos pocos años antes - se han venido publicando numerosos estudios politológicos relacionados con la comunicación de masas ${ }^{7}$. Como señala Doris Graber —en el más reciente state of art de la disciplina avalado por la American Political Science Association- a pesar de que la Comunicación Política es una de las áreas más veteranas de los estudios políticos, como subdisciplina de la Ciencia Política es una de las más jóvenes y en mayor progresión ${ }^{8}$.

En 1981 se publica una obra seminal; se trata del Handbook of Political Communication, compilado por Nimmo y Sanders". En este libro se daba cuenta del desarrollo y emergencia de la Comunicación Política como un

${ }^{6}$ Por citar algunos, recordemos el monográfico sobre cine de The Annals of the American Academy of Political and Social Science en 1947, o artículos y obras aisladas como la de Douglas Waples (ed.): Print, Radio, and Film in a Democracy (Chicago, The University of Chicago, 1942); M. Meucci, Political Cinematology. How Motion Pictures and Television Will Shape the Political Destiny of America (Nueva Jersey, Newark, 1943); R. FiELDING, "Mirror of Discontent», en Western Political Quarterly, 1959; o A. GuILlot, "Aspects politiques du cinéma américain", en L'Année Sociologique, 1960. En nuestro país tenemos incluso la perspectiva falangista de Ernesto Giménez Caballero, Cine y política, publicada como separata de la Revista de Estudios Políticos, núm. 19, 1945.

7 Ya en 1972 la literatura norteamericana sobre el tópico contaba con miles de artículos. Para una somera revisión de esta literatura en la década de los setenta, véase Dan NimMO, «Mass Communication and Politics», en Samuel L. Long (ed.): The Handbook of Political Behavior, Nueva York, Plenun Press, 1981. Para la década de los ochenta, véase Anne JoHnSON, «Trends in Political Communication: A Selective Review of Reseach in the 1980's», en D. L. SWANSON y D. Nimmo (eds.): New Directions in Political Communication, Londres, Sage, 1990.

8 Doris Graber, «Political Communication: Scope, Progress, Promise», en Ada W. FinifTer (ed.): Political Science: The State of Discipline, Washington, APSA, 1993, p. 306.

9 Dan Nimmo y Keith R. SANDERS (eds.): Handbook of Political Communication, Londres, Sage, 1981. 
campo de investigación con perfiles propios aunque situado en las fronteras académicas de varias ciencias sociales (entre ellas, como señalaba Graber, la Ciencia Política). Según este estado de la cuestión, el ámbito de estudio del nuevo campo eran las relaciones entre proceso comunicativo y proceso político, tomando las campañas electorales y políticas como su caso paradigmático. Con semejante proyecto, no es de extrañar que la mayor atención se prestase a lo que podríamos denominar como mensajes políticos explícitos (discursos políticos, mítines, debates entre candidatos, publicidad e información política, etc.), postulando como técnicas adecuadas el análisis de contenido cuantitativo o - más cualitativamente- el análisis retórico del discurso.

Sin embargo, desde principios de la década de los años ochenta, algunos enfoques cada vez más prominentes de la Comunicación Política se han significado por su intento de superar el así llamado "paradigma de la persuasión del votante» ${ }^{10}$. Esta superación conlleva una ampliación del campo de investigación y de los objetos de estudio, permitiendo filtrarse bajo el paraguas académico de la Comunicación Política a perspectivas más radicales y menos administradas como pueden ser los Cultural Studies neo-marxistas, los análisis de economía política de los medios, los estudios franceses y alemanes basados en la noción de espacio público, la crítica ideológica de inspiración francfortiana o las sucesivas reformulaciones del estructuralismo y post-estructuralismo ${ }^{11}$.

Como resultado de este proceso de ampliación de miras se producen cambios en algunas premisas básicas de la Comunicación Política hasta entonces consolidada en Estados Unidos. Según Morley ${ }^{12}$, los dos principales cambios son: de un lado, el reciente reconocimiento de la considerable significación política de un amplio espectro de productos culturales, con el consecuente interés por el entretenimiento y la ficción popular; de otro lado, el reconocimiento cada vez mayor de la naturaleza compleja y contradictoria del consumo cultural, lo que revela la limitada utilidad analítica del modelo del proceso comunicativo formulado por Lasswell.

Con estas nuevas premisas, el cine encuentra un lugar claro en los objetos de interés politológico, ya que es ejemplo paradigmático de ficción y entretenimiento popular. Obviamente, los discursos de la comunicación pública basados en la ficción no sustituyen a los hechos ni a las conductas que tanto interesan a las ciencias sociales, ni a la política institucional. Sin embargo —como nos indica Whitebrook a propósito de la novela y la pintura- este tipo de

10 Vid. Dan Nimmo y David L. Swanson, «The Field of Political Communication: Beyond the Voter Persuasion Paradigm», en SWAnson y Nimmo (eds.): op. cit.

${ }_{11}$ Para un balance de la situación académica de la Comunicación Política en Francia y Alemania en los años noventa y la influencia en la misma de las tradiciones intelectuales nacionales, véase Winfried SCHULZ, "Political Communication Scholarship in Germany», en Political Communication, vol. 14, 1997; Roland CAYrol y Arnaud MerCIER, "Political Communication Scholarship in France», en Political Communication, vol. 15, 1998.

12 David Morley, "The Construction of Everyday Life: Political Communication and Domestic Media», en Swanson y Nimmo (eds.): op. cit., p. 129. 
expresiones basadas en la ficción permiten al politólogo una comprensión mucho más completa del mundo real de la política ${ }^{13}$.

Cabría preguntarse el por qué de esta tardanza en asumir algo tan obvio y enriquecedor para la comprensión científica de la política. Ya apuntamos algunos motivos específicos que pueden explicar el desinterés politológico por el cine, pero Gronbeck nos aporta una clave de carácter más general: el psicologismo de la investigación académica ${ }^{14}$. El predominio del enfoque behavioralista motivó que la reflexión teórica y la investigación empírica se centrasen en aspectos muy concretos (sobre todo, el cambio de actitud y opinión), en lugar de facilitar una extensión imaginativa de los objetos de estudio. Por este motivo, hasta bien entrada la década de los ochenta, la investigación de la pertinencia política de los medios populares había sido «difusa, asistemática, a menudo impresionista, y centrada en buena medida en los presumibles o hipotéticos efectos sobre la audiencia ${ }^{15}$ ". Como reclaman Savage y Nimmo, hoy día se requiere un ejercicio de imaginación politológica para aunar los esfuerzos dispersos de lo que ellos etiquetan como invisible colleges (centrados en política y cine, política y música, política y literatura, etc.), con las reflexiones culturales generales más abstractas de escuelas teóricas como pudieron ser en su momento las de Francfort o Chicago ${ }^{16}$. Este giro culturalista era patente a principios de la década de los noventa no sólo en el ámbito de los Cultural Studies sino también en la investigación sobre comunicación de masas tradicional ${ }^{17}$, e incluso en los estudios de Comunicación Política desarrollada dentro del ámbito disciplinar de la Ciencia Política estadounidense ${ }^{18}$.

Los problemas que se pueden presentar a la hora de integrar los estudios sobre cultura popular en la Ciencia Política son más de orden académico que

13 Maureen Whitebrook, «Introduction», en Whitebrook (ed.): Reading Political Stories, Lanham, Rowman and Littlefield, 1991, p. 5. Para esta autora, la ficción no aporta hechos políticos como tales sino "la realidad presentada por medio de un tipo diferente de evidencia y por tanto capaz de ofrecer un realismo diferente y más completo".

${ }^{14}$ Literalmente: «Los investigadores de este país [se refiere a Estados Unidos, aunque esta reflexión podría ser válida para otros países] probablemente tomaron el camino equivocado cuando estudiaron la cultura popular y los medios; su interés por los efectos psicológicos de los medios (...) les condujeron hacia el interior y no hacia el exterior. Esta vía interiorista hacia los mundos subjetivos del gusto y el placer, explica por qué los estudiosos americanos se retrasaron tanto al estudiar la dimensión política de lo popular». Bruce E. GronBECK, «Popular Culture, Media and Political Communication», en SWANSON y Nimmo (eds.): op. cit., p. 186.

15 Robert L. Savage y Dan Nimmo, «Imagination, Politics and Popular Media: A Thematic Introduction», en SaVage y Nimmo (eds.): Politics in Familiar Contexts, p. 2.

${ }_{16}$ Para un resumen de las reflexiones teóricas generales de las citadas escuelas sobre el tema de la relevancia política de la cultura de masas, vid David L. SWANSON, «Popular Art as Political Communication", en Savage y Nimmo (eds.): Politics in Familiar Contexts, pp. 13-61.

17 Véase la excelente propuesta metodológica para superar el behavioralismo de tales estudios en el ámbito de la cultura popular de Dennis K. DAvis y Thomas F. N. PUCKETT, «Mass Entertaiment and Community: Toward a Cultured-Centered Paradigm for Mass Communication Research", en Stanley A. DeETz (ed.): Communication Yearbook/15, Londres, Sage, 1992.

18 Graber, op. cit., pp. 311 y 312. 
meramente científico. Como señalan Mujerki y Schudson para el caso de Estados Unidos, cada disciplina académica ha utilizado el emergente interés por la cultura popular como arma arrojadiza en sus propias guerras intradisciplinares: «los estudiosos de la cultura popular de todos los ámbitos académicos se han visto a sí mismos como innovadores, marginales (...) y misioneros dentro de sus propias disciplinas, empleando nuevos temas e ideas importadas de otras disciplinas para cuestionar el estándar de las suyas propias ${ }^{19}$ ».

Estos debates académicos, espoleados por el auge de estudios transversales como los Cultural Studies o los denominados Post-Colonial Studies, así como por la consolidación de nuevos campos de investigación como la Comunicación Política, apenas han comenzado a tener su reflejo fuera del mundo anglosajón. Sin embargo, creemos que tales disputas identitarias no deben ser planteadas en términos de a qué disciplina cabe adscribir prioritariamente esos estudios o de si son o no son Ciencia Política. Las fronteras de la Ciencia Política como la del resto de las ciencias sociales son abiertas y no necesitan ser definidas defensivamente. El proceso de especialización acaecido desde el declive de la hegemonía del enfoque politológico behavioralista a finales de los años sesenta ha generado una creciente fragmentación de sus campos de interés que, lejos de ser amorfos, están bien organizados y son altamente creativos. La heterogeneidad se ha nutrido en buena parte de los intercambios con disciplinas vecinas, tendiendo puentes entre áreas especializadas de varias ciencias sociales. La continua reestructuración de la Ciencia Política actual es el resultado de la interación de estos procesos de fragmentación, especialización e hibridación. En el pasado la interacción se daba entre disciplinas completas o partes sustantivas de las mismas, por lo que era necesario hablar de interdisciplinaridad. En la actualidad, sin embargo, la interacción se da entre subcampos altamente especializados de disciplinas vecinas. Estos híbridos - muy numerosos pero periféricos del cuerpo tradicional de la disciplina-, lejos de permanecer aislados en mesas separadas dialogan continuamente con sus vecinos ${ }^{20}$.

\subsection{Principales corrientes en el estudio de la relación entre cine y politica}

Debemos partir de la constatación de que el campo de la Comunicación Política es diverso, permeable y en constante expansión. Por este motivo, utili-

19 Chandra Mukerji y Michael Schudson, Rethinking Popular Culture. Contemporary Perspectives in Cultural Studies, Los Ángeles, University of California Press, 1991, p. 4.

${ }^{20}$ Dentro de los debates estadounidenses sobre la identidad de la Ciencia Política esta celebración de la diversidad y fragmentación es sostenida consistentemente — contra Almond y otros - por Mattei Dogan en "Political Science and the Other Social Sciences», en Robert E. Goodin y Hans-Dieter KuIngemann (eds.): A New Handbook of Political Science, Londres, Oxford University Press, 1996. 
zaremos de modo meramente descriptivo la amplia división que Nimmo y Swanson trazan entre la corriente dominante (mainstream) y la corriente radi$\mathrm{cal}^{21}$. Esta clasificación, más que fundamentarse en rigurosas premisas metodológicas o teóricas, se basa en la atribución de características y objetivos diferenciados: la corriente dominante sería más conservadora, más empírica, orientada hacia la política explícita, con una visión liberal pluralista de la sociedad y dominante académicamente; la corriente radical se apoyaría en posiciones de izquierda, orientada hacia la comunicación pública entendida como reproducción de la hegemonía, más interesada por la ficción y el entretenimiento. Esta ultima corriente se imbrica inextricablemente en el mundo anglosajón con estudios trasversales como los Cultural Studies o con determinados aspectos de los Film Studies. Como se ve, la distinción es arbitraria y admite bastantes excepciones. Sin embargo, al menos, nos ayuda a introducir descriptivamente la situación.

Para Nimmo y Swamson, la tendencia mainstream de la Comunicación Política — más allá de sus importantes diferencias internas - se caracteriza por estudiar los usos estratégicos de la comunicación para influir en el conocimiento público, las creencias y la acción en asuntos políticos, y por considerar la campaña política como el ejemplo paradigmático de este campo ${ }^{22}$. El campo básico de investigación de los enfoques dominantes incluiría temas como la fijación de la agenda política, los efectos de la publicidad y marketing político, el análisis retórico del discurso político, relaciones entre prensa y políticos, impacto de las campañas en el voto, comunicación dentro de las instituciones políticas, efectos socializadores de la información política, etc.

Sólo recientemente algunos investigadores estadounidenses insertos en la tradición dominante han prestado atención a la dimensión política de la cultura popular y de masas, aunque sin olvidar del todo la preocupación por los efectos políticos mesurables de estos productos comunicativos. Ejemplos recientes podrían ser las obras de Edsforty y Bennet ${ }^{23}$, Parenti ${ }^{24}$, Christiansen ${ }^{25}$, Prindle $^{26}$ o Nimmo y Combs ${ }^{27}$. Quizá sean estos dos últimos autores los que

${ }^{21}$ Nimmo y Swanson, «The Field of Political Communication: Beyond the Voter Persuasion Paradigm", en SWANSON y Nimmo (eds.): op. cit.

${ }^{22}$ Ibidem, p. 8.

${ }^{23}$ Ronald Edsforty y Larry Bennet (eds.): Popular Culture and Political Change in Modern America, Albany, State University of New York Press, 1991.

${ }^{24}$ Michel Parenti, Make-Believe Media: The Politics of Entertaiment, Nueva York, St. Martin Press, 1992.

25 Terry Christiansen, Reel Politics. American Political Movies from The Bith of a Nation to Platoon, Nueva York, Basil Blackwell, 1987.

26 David F. PRINDle, Risky Business. The Political Economy of Hollywood, Boulder, Westview Press, 1993.

27 Dan Nimmo y James E. Combs, Mediated Political Realities, Nueva York, Longman, 1990. Véanse también las obras de Combs: American Political Movies (Nueva York, Garland Publishing, 1990); Polpop: Politics and Popular Culture in America (Bowling Green, Bowling Green University Popular Press, 1984); y su continuación de 1991, Polpop 2: Politics and Popular Culture in America Today. 
han alcanzado mayor difusión académica en Estados Unidos con su noción de realidades politicas mediadas.

Nimmo y Combs parten de la evidencia de que las imágenes mentales que la gente tiene de la política rara vez son producto de la experiencia directa sino de la mediación. La mayoría de las percepciones son filtradas y «fantaseadas» por una serie de mediadores tanto grupales y personales (movimientos políticos, religiosos, líderes de opinión, etc.) como mass-mediáticos (cine, radio, televisión, discos, revistas, posters, etc.). La mediación comunicativa de la política no se refiere sólo al género informativo sino — sobre todo y fundamentalmenteal entretenimiento y la ficción. El cine es para Nimmo y Combs una forma de mediación política que nos revela las estrategias y rituales del poder. Por tanto, las películas y los productos de la cultura de masas contribuyen decisivamente a la formación de un imaginario político a través del cual los individuos dotan de sentido al mundo que está más allá de su experiencia inmediata y, por ende, interpretan el proceso político y a sus actores. Es más, la identidad política colectiva viene dada también por las representaciones mediadas de la Historia que se ofrecen como referencia común a la memoria colectiva. En este tipo de representaciones el cine también funciona como un potente mediador del imaginario colectivo a la hora de construir la identidad de una comunidad.

Dentro del mainstream de la Comunicación Política se han dado otras interesantes aproximaciones al cine. Politólogos como Savage o Neve han realizado interesantes reflexiones acerca de las dimensiones políticas de los géneros y estereotipos cinematográficos ${ }^{28}$, aunque probablemente el reader más ambicioso sea Movies and Politics: the Dynamic Relationship, coordinado nuevamente por el especialista James E. Combs ${ }^{29}$.

Podemos citar, por último, otras relaciones tangenciales del cine con la Ciencia Política en la medida en que éste se relaciona con otros tópicos no abarcables estrictamente por la Comunicación Política. Podría ser el caso de la socialización política a través de la comunicación de masas ${ }^{30}$, el desarrollo socio-económico a través del cine ${ }^{31}$, el apoyo económico estatal al cine en tanto

28 SAVAgE, "The Stuff of Politics Through Cinematic Imagery», en particular las pp. 125 y ss. Brian Neve, Film and Politics in America. A Social Tradition, Londres, Routledge, 1992. (Sus estudios sobre los filmes clásicos de Frank Capra y sobre los aspectos políticos del cine negro son ejemplares.) Otro estudio ejemplar dentro de este enfoque es la obra coordinada por Davies y Neve, Cinema, Politics and Society in America (Manchester, Manchester University Press, 1981), que compila valiosos análisis politológicos de diversos aspectos de la industria americana del cine, aportando una interesante dimensión histórica.

${ }^{29}$ James E. Combs (ed.): Movies and Politics: the Dynamic Relationship, Nueva York, Garland Publishing, 1993.

${ }^{30}$ Hyman recoge algunos casos de socialización política en el tercer mundo a través de filmes publicitarios y de ficción, reconociendo la influencia política de contenidos no políticos. Herbert HYMAN, «Los medios de masa y la socialización política», en Lucian W. PYE (ed.): Evolución politica y comunicación de masas, Buenos Aires, Troquel, 1969.

${ }_{31}$ Se trata de utilizar el cine como instrumento de las teorías del desarrollo auspiciadas por la ONU. Vid. P. Hopkinson, The Role of Film in Development, Nueva York, UNESCO, 1972. 
política pública cultural ${ }^{32}$ o el uso pedagógico de las películas en la enseñanza de la Ciencia Política ${ }^{33}$.

Los investigadores de la corriente crítica o radical se caracterizan por su oposición al enfoque dominante centrado en las campañas políticas y electorales. A menudo, tal oposición teórica y metodológica conlleva incluso el que rara vez los críticos se sitúen a sí mismos dentro del campo académico de la Comunicación Política. Como señalamos anteriormente, la consolidación de estudios transversales en las universidades anglosajonas ha complicado aún más las adscripciones académicas de los campos de estudio. No obstante, retomando la distinción de partida propuesta por Nimmo y Swanson, podemos sintetizar al menos tres divergencias fundamentales entre el mainstream y la corriente crítica que derivan en el fondo de su antagonismo ideológico:

1. El que el «paradigma de la persuasión del votante» (campañas electorales) defina los límites y la agenda académica del campo de la Comunicación Política nos impide ver el auténtico papel que la comunicación desempeña en las democracias occidentales. Para una buena parte de los $\operatorname{críticos}^{34}$, la función más importante de las campañas electorales y de la información política no es ofrecer las diferentes alternativas de los candidatos sino hacer presente la política a las masas según las lógicas del drama y del espectáculo. De esta manera, a través de los rituales dramáticos-espectaculares que son las elecciones, se legitima el sistema político y se apuntala el mito liberal de la capacidad colectiva de autodeterminación. Sin embargo, estos aspectos comunicativos centrados en los actores políticos clásicos y en las campañas electorales no son el elemento más decisivo para estudiar las relaciones de poder en la sociedad. Los estudios culturales se interesan por la forma en que las divisiones sociales son dotadas de sentido. En líneas generales, la cultura popular es entendida como el espacio comunicativo en el que la clase, el género, la raza, la discapacidad física - o cualquier otro aspecto social que suponga relaciones desiguales de poder entre colectivos - son representados, construidos y naturalizados en el discurso público. Se trata, por tanto, de analizar cómo a través de las representaciones sociales compartidas se construyen las identidades individuales y colectivas. Estas prácticas significantes no son ingenuas sino que se realizan mediante el conflicto simbólico entre los discursos del poder — legitimadores- y algunos discursos de resistencia. Con tales planteamientos no es extraño que se hayan exhumado y reformulado nociones como las de ideología y hegemonía. A diferencia de los tradicionales enfoques marxistas, para el enfoque culturalista crí-

32 Objeto de análisis de políticas públicas puede ser también el estudio de la colaboración burocrática estatal en el rodaje de ciertas películas. Vid. Nimmo, «Mass Communication and Politics», p. 272.

${ }_{33}$ M. A. GenOvese, "Teaching Politics with Films», en News for Teachers of Political Science, núm. 1 (40), 1984.

${ }^{34}$ Vid. vgr. James CurRan y otros (eds.): Sociedad y comunicación de masas, México, Fondo de Cultura Económica, 1981. 
tico la ideología no es definida normativamente de manera peyorativa (como falsa conciencia) ni concebida como una abstracción poco verificable empíricamente, sino más bien como una práctica cotidiana perfectamente verificable que admite alternativas y estrategias de oposición.

Este tipo de perspectivas culturalistas han sido etiquetados en ocasiones dentro de la Ciencia Política como cultural politics, en contraste con el enfoque clásico de cultura política (political culture). En el enfoque de la política de la cultura, lo político no se convierte en adjetivo sino que se amplía hasta abarcar prácticas colectivas anteriormente consideradas ajenas a las relaciones de poder dentro de la comunidad ${ }^{35}$.

2. Una segunda oposición a la corriente académicamente dominante en Comunicación Política se centra en la supuesta asepsia cientificista de tales estudios $^{36}$. Esta crítica nos remite a la clásica cuestión del compromiso democrático de las ciencias sociales; debate que fue reavivado en los años ochenta desde diversos frentes al calor de las guerras sobre las identidades disciplinares. No obstante, los culturalistas contemporáneos no plantean el problema en términos de compromiso de la ciencia con los problemas de la democracia (como ocurrió con los críticos del behavioralismo a finales de los años sesenta o con historiadores disciplinares como David Ricci o Raymond Seidelman dos décadas después). El rescate y reformulación de la noción gramsciana de hegemonía presupone que la cultura popular es un ámbito discursivo en el que cabe cierta capacidad de resistencia e incluso de transformación, y no únicamente un lugar para la alienación y la reproducción de la desigualdad. Por consiguiente, el analista crítico deviene activista político en la medida en que ofrece estrategias de resistencia y decodificación de los discursos del poder $^{37}$.

3. Una tercera y última oposición radical viene dada por el cuestionamiento de la premisa básica que consiste en medir los efectos e influencia de los media. Intentar aplicar al cine la noción behavioralista de efectos observables en la actitud y la conducta lleva a un callejón sin salida; y ello por dos motivos. En primer lugar, porque metodológicamente es muy difícil analizar la presunta influencia del entretenimiento: ni se puede medir inequívocamente su influencia cognitiva acumulativa a largo plazo, ni tampoco la noción de cambio de actitud ha sido reformulada para el ámbito de la ficción de una manera lo suficientemente sutil como para darnos alguna clave generalizable ${ }^{38}$.

35 Véase la revisión de la literatura sobre el tema realizada por John Street, «Review Article: Political Culture - from Civic Culture to Mass Culture», en British Journal of Political Science, núm. 24, 1993.

36 Véase Donald LAZARE, «Introduction: Entertainment and Social Control», en LAZARE (ed.): American Media and Mass Culture. Left Perspectives, Los Ángeles, University of California Press, 1987.

37 Esta fue la conocida propuesta de Stuart Hall, uno de los reconocidos fundadores de los Cultural Studies británicos. Más recientemente analistas como Douglas Kellner o Henry Giroux propugnan una nueva "pedagogía crítica de los medios» como forma de cultivar una ciudadanía democrática apropiada para las sociedades actuales colonizadas por la cultura mass-mediada.

38 Probablemente, el mejor intento de análisis de los efectos acumulativos a largo plazo de la 
En segundo lugar, porque entender la relación entre cine y política desde una perspectiva de causa a efecto nos lleva ineludiblemente a precisar qué hace de un filme concreto un hecho político: ¿la intención del autor o las hipotéticas consecuencias del filme en el público? Esta falsa e insoluble oposición impide ver los verdaderos aspectos políticos del cine ${ }^{39}$.

De las críticas señaladas en los puntos precedentes es fácil deducir el lógico interés de la corriente crítica por las formas «no políticas» de la comunicación popular y su preferencia por metodologías y técnicas de análisis diferentes al empirismo de la Comunicación Política tradicional. En un primer momento, se retomaron los análisis gramscianos (teoría de la hegemonía) o althusserianos (reproducción de las condiciones de producción a través de los Aparatos Ideológicos del Estado), tan en boga a finales de la década de los sesenta y en buena parte de los años setenta, como marco conceptual de referencia. De hecho, desde estos enfoques marxistas el cine era concebido como otro Aparato Ideológico del Estado: el llamado Aparato Cinematográfico ${ }^{40}$. Simultáneamente, los análisis semiológicos y estructuralistas ofrecían el arsenal metodológico apropiado y distintivo.

No obstante, los enfoques críticos actuales han cambiado de enfoque, haciendo suyos algunos de los cambios teóricos básicos en el estudio de la relación entre política y comunicación (en donde sitúan al cine) acaecidos desde el declive del estructuralismo. Estos cambios podemos sintetizarlos en tres grandes bloques:

1. Desde el punto de vista de la valoración de la cultura popular se ha pasado de un elitismo cultural — que hunde sus raíces en el pensamiento francfortiano ${ }^{41}$ - y de un estigma de alienación ineludible a una concepción

cultura de masas en la percepción social de la realidad — realizado desde la Communication Research — han sido la «teoría de los indicadores culturales» y el denominado "análisis de cultivo» impulsados por George Gerbner. Partiendo de unas premisas críticas para el análisis de la legitimación del poder a través de la comunicación en las sociedades contemporáneas, Gerbner trata de ofrecer una investigación empírica rigurosa de carácter científico más que especulativo. Sin embargo, muchos de los críticos Gerbner señalan que acaba cayendo en un cierto automatismo al aplicar la noción clásica de efectos sobre las actitudes; noción que parecía superar en sus presupuestos teóricos y a la que finalmente no encuentra sustitución. Por otra parte, algunos críticos señalan que sus hipótesis no se confirman en contextos diferentes al estadounidense. Véase Rafael Roda FERnÁNDEZ, Medios de comunicación de masas. Su influencia en la sociedad y en la cultura contemporáneas, Madrid, CIS/Siglo XXI, 1989, pp. 329 y ss. También se recogen críticas parecidas en Mauro Wolf, Los efectos sociales de los media, Barcelona, Paidós, 1994, pp. 99 y ss.

39 Folke Isaksson y Leif Furhammar, Politics and Film, Londres, Studio Vista, 1971, p. 240. Estos autores resuelven salomónicamente el dilema afirmando que es cada situación concreta — el contexto- la que crea la función y relevancia política de cada película.

${ }^{40}$ Véase la orientación del conocido libro El Aparato Cinematográfico español (Madrid, Akal, 1976) del colectivo Marta Hernández. Vid. también "Cine, ideología, política», en Cahiers du Cinéma, núm. 232 (incluido en la antología de textos de VV.AA.: Los años que conmovieron al cinema, Valencia, Filmoteca de la Generalitat, 1988).

${ }^{41}$ Nos referimos sobre todo a la crítica a las industrias culturales de Adorno y Horkheimer; otros autores, como Benjamin o Kracauer, están mucho más abiertos al cine comercial. 
más abierta y tolerante de la cultura de masas; hecho que algunos han etiquetado críticamente como populismo cultural $^{42}$. La reformulación de la noción de hegemonía ha sido sin duda la que ha propiciado esta nueva evaluación de la cultura de masas, entendida como espacio de discursividad en el que cabe la confrontación ideológica. Sin embargo, desde ámbitos europeos más cercanos a la teoría crítica de los medios y más alejados de la tradición anglosajona de los Cultural Studies, la noción teórica de espacio público es la que está permitiendo la revalorización de la cultura popular. Partiendo de la formulación habermasiana desarrollada en su obra temprana Historia y crítica de la opinión pública (1962), a mediados de la década de los ochenta la noción fue redefinida tras las numerosas críticas recibidas desde el pensamiento feminista, crítica postmoderna, o por parte de los historiadores y sociólogos de la comunicación de masas ${ }^{43}$. Son particularmente valiosas las aportaciones de la revista francesa Hermès $^{44}$, editada por Dominique Wolton, en las que desde una perspectiva multidisciplinar se han publicado numerosos estudios presididos por la noción de nuevo espacio público, aunque su interés por el cine es tangencial y se enmarca en el análisis más general sobre el estatuto de la imagen. La traducción al inglés en 1989 del citado libro de Habermas generó una notable difusión de la noción de espacio público en la literatura anglosajona sobre comunicación. Quizá por este motivo se tradujo la obra de Oskar Negt y Alexander Kluge, Öffentlichtkeit und Erfahrung ${ }^{45}$, publicada originalmente en 1972, en la que se plantea la existencia de diversas esferas públicas alternativas o de oposición como estrategia política frente a la dominación. La peculiaridad de esta obra residía, por un lado, en que sintonizaba con las recientes investigaciones sobre la denominada comunicación política alternativa ${ }^{46}$ —a las que ofrecía un marco

${ }^{42}$ Jim McGuigan, Cultural Populism, The Effects of Gramscianism on Cultural Studies, Londres, Routledge, 1992.

43 Algunas de estas críticas han sido sintetizadas por John B. Thompson en «La teoría de la esfera pública», en Voces y culturas, núm. 10, 1996 (publicado originariamente en Theory, Culture \& Society, vol. 10, 1993). El propio Habermas reconocía algunos argumentos de sus críticos en el Prefacio a la edición alemana de 1990 (recogido en la 4. ${ }^{a}$ edición española de 1994). Una interesante crítica de la noción habermasiana apareció en el monográfico de la paradigmática revista estadounidense Social Text (núm. 25-26, 1990) con el título "The Phantom Public Sphere».

${ }^{44}$ La revista es publicada desde su fundación en 1988 por el Centre National de Recherches Scientifique. Desde una perpectiva multidisciplinar se ha centrado en temas como la relación entre democracia y esfera pública, imágenes y política, defensa de los medios de comunicación de titularidad pública, etc. No obstante, este enfoque sigue siendo minoritario en la investigación en comunicación política francesa. Los marcos teóricos de referencia suelen seguir a menudo las estelas de Boudieu y su constructivismo estructuralista o a Norbert Elias y sus «modelos de figuración». Para una revisión de las escuelas académicas de los estudios actuales sobre comunicación política en Francia véase Erik NeveU, "Media and politics in French political science», en European Journal of Political Research, núm. 33, 1998.

45 The Public Sphere and Experience, Minneapolis, University of Minnesota Press, 1993.

${ }^{46}$ Andrew KING (ed.): Postmodern Political Communication. The Fringe Changes the Center, Londres, Praeger, 1992. El subtítulo de este libro da una pista de la noción de comunicación política postmoderna que emplean sus autores: aquellos discursos periféricos a los espacios discursivos institucionalizados por los grupos dominantes. Ideas parecidas fundamentan libros 
teórico sólido-, y de otro lado, en el hecho de que el propio Kluge era un cineasta radical. Las reflexiones de Kluge en torno al papel del cine en la construcción de espacios públicos alternativos ${ }^{47}$ han tenido una cierta —aunque limitada - repercusión en los estudios sobre cine y política a través de analistas como Miriam Hansen o el influyente John Fiske ${ }^{48}$.

2. Un segundo cambio básico que recogen las diversas corrientes críticas de la Comunicación Política y Estudios Culturales es la superación del paradigma estructuralista interesado prioritariamente por los mecanismos textuales de producción de significado, en pos de una visión multidimensional que incluye otros aspectos (vgr. tematización y conformación de la agenda del espacio público, análisis del consumo y recepción de los productos culturales desde un punto de vista antropológico, representación de colectivos y atribución de identidades, intertextualidad entre los discursos de la cultura de masas y el discurso informativo, análisis de las condiciones de producción de los productos comunicativos, etc.).

3. Finalmente, podemos citar el cambio en la perspectiva de análisis del proceso comunicativo, pasando de un enfoque fundamentado en el lenguaje verbal a una visión que entiende la comunicación de masas como una práctica discursiva distinta, peculiar y heterogénea. En este mismo sentido - apostando por la tradición de los Cultural Studies de Stuart Hall más que por el legado estructuralista-, la corriente crítica aboga por la idea de espectador empirico como alguien activo inserto en procesos de comprensión dados por su situación social (clase, raza, género, subcultura, etc.). Por tanto, el significado de los discursos no se concibe como algo inmanente al texto, sino como un proceso negociado de atribución de sentido a partir de unos códigos dados no sólo por la psicología individual sino por la situación de clase, raza o género (o cualquier adscripción basada en relaciones desiguales de poder que configuren nuestra subjetividad).

Acabamos de citar algunos de los principales cambios teóricos en la cuestión de la relación entre política y comunicación, cambios que han sido adoptados (desde muy diversos ángulos, desde luego) por la corriente crítica radical interesada por la comunicación política. Una de las más exitosas y brillantes ideas que se desprenden de las asunciones teóricas precitadas es la de entender la cultura mass-mediada no como un ámbito de ineludible alienación sino

como el de Sara M. Evans y Harry C. BoyTe, Free Spaces. The Sources of Democratic Change in America, Chicago, The University of Chicago Press, 1992.

47 Véase Alexander Kluge, "On Film and Public Sphere», en New German Critique, núm 24-25, 1981. Muy esclarecedora es la entrevista realizada por Stuart LIEBERMAN, «On New German Cinema, Art, Enlightment, and the Public Sphere: an interview with Alexander Kluge», en el monográfico sobre Kluge de October, núm. 46, 1988.

48 Véase Miriam HANSEN, "Early cinema, late cinema: permutations of the public sphere», en Screen, vol. 34, núm. 3, 1993. John FISKE, Power Plays, Power Works, Nueva York, Verso, 1990. 
como un espacio discursivo dinámico; espacio en el que cabe, en cierto grado, la confrontación simbólica. Estas ideas, popularizadas en la literatura anglosajona a partir de las trabajos seminales de Hall ${ }^{49}$, han evolucionado en medio de un intenso debate en el seno los Cultural Studies, distanciándose cada vez más de los teóricos marxistas estructuralistas de referencia a principios de los años setenta y acercándose a posiciones foucaultianas. Desde este punto de vista, el cine sería una de las más poderosas "tecnologías del self» — según el sentido que Foucault atribuye a este concepto- a través de las cuales el orden social establece los tipos de subjetividades necesarias para su perpetuación. Dentro de los nuevos exponentes de la corriente crítica - heredera pero permanentemente superadora de estos debates - se encontrarían el ya citado Fiske, para el campo de la televisión, o Michael Ryan, Douglas Kellner, Mas'ud Zavarzadeh o el teórico Noël Carroll, para el ámbito del cine $e^{50}$.

Ryan y Kellner son autores de una difundida investigación sobre la política e ideología de las películas contemporáneas de Hollywood. Sin embargo -a diferencia de Kellner, más cercano a la teoría crítica ${ }^{51}$ - Ryan se ha preocupado por las posibilidades de contestación discursiva y no sólo de la decodificación negociada de los textos fílmicos o de la lectura política crítica del filme, como hizo en la citada Camera Politica. Para Ryan, las teorías de Stuart Hall conducen necesariamente a analizar la cultura popular como un mero lugar o región de resistencia a la dominación. Si bien los conceptos de ideología (Althusser) y hegemonía (Gramsci) superan el economismo más mecanicista, necesariamente son modelos de praxis política del tipo top-down (es decir, de arriba a abajo) necesitados de una élite o vanguardia intelectual. Ryan — desde la realidad estadounidense en la que se inserta- postula la necesidad de teorizaciones diferentes que puedan dar lugar a modelos más adecuados de intervención

49 En particular del celebrado «Encoding/Decoding», recogido en Stuart Hall y otros (eds.): Culture, Media, Languaje, Londres, Hutchinson, 1980. Según Hall, existen tres posibles modos de decodificación negociada de los textos mediáticos: a) Sistema dominante: aceptación acrítica de la versión oficial de las relaciones de clase que difunden los medios; b) Sistema de subordinación: aceptación del esquema moral que ve la sociedad como una estructura de beneficios aunque, por contra, se cuestiona el reparto de los mismos; c) Sistema radical: decodificación de oposición sustentada en la conciencia de clase.

${ }^{50}$ John Fiske, Television Culture, Londres, Methuen, 1987; Michael RYAN y Douglas KeLLNER, Camera Politica; También RYAN, "The Politics of Film: Discourse, Psychoanalisis, Ideology", en Cary NeLSON y Lawrence Grossberg (eds.): Marxism and the Interpretation of Culture, Chicago, University of Illinois Press, 1988; Mas'ud ZavarZadeh, Seeing Films Politically, Nueva York, State University of New York Press, 1994; Noël Carroll, Theorizing the Moving Image, Nueva York, Cambridge University Press, 1996. Además de estos autores podemos encontrar numerosas investigaciones radicales en el mundo anglosajón sobre cine y política, vid. vgr. la antología de artículos sobre cine recogidos en el capítulo 3, "Moments of the Historical Conciousness", en Donald Lazere (ed.): American Media and Mass Culture: Left Prespectives, Los Ángeles, University of California Press, 1987, pp. 157 y ss.

51 Véanse sus análisis de películas y su propuesta de una pedagogía crítica de los medios en el notable Media Culture. Cultural Studies, Identity and Politics between the Modern and the Postmodern, Londres, Routledge, 1995. 
política. En palabras del propio autor, el primer paso necesario en esta dirección sería reemplazar la orientación top-down de la teoría británica por una orientación que tome como punto de partida las energías, necesidades y deseos que operan en un nivel popular, concibiendo aquellas energías como la fuerza productiva que genera la sociedad. Esta estructura conceptual diferente prescribe una estrategia más del tipo bottom-up (de abajo a arriba); estrategia que pudiese ver la base popular como el primer término de cualquier posible ecuación política y no como un mero lugar de una (generalmente fallida) resisten$\mathrm{cia}^{52}$.

Como podemos ver, la inserción de los estudios fílmicos en la Ciencia Política a través de las distintas corrientes de la Comunicación Política es algo vivo, lejos de ser una excentricidad propia de politólogos cinéfilos. El cine se sitúa - junto con otros medios de comunicación- en el debate teórico y práctico sobre el conflicto político en el seno de la cultura popular y del nuevo espacio público (o unificando ambos conceptos bajo una única etiqueta, en el seno de la cultura mass-mediada). Ficción, entretenimiento o imaginario, no deben ser palabras ajenas al análisis y estudio de la política, máxime cuando hoy día la noción clave de representación política está manifestando cada vez más su carácter visual y espectacular ${ }^{53}$ (en el sentido premoderno de "publicidad representativa» del que nos habla Habermas). Las llamadas videodemocracias no son la perversión de ninguna arcadia democrática perdida, sino la constatación viva de la necesidad de utilizar nuevos elementos de análisis para comprender la política en las sociedades occidentales actuales. Desvelar la dimensión espectacular, simbólica y dramática de la política (al modo de Schwartzenberg o Edelman) no es airear una corrupción de la democracia, sino dar paso a un torrente de nociones tradicionalmente ignoradas o despreciadas y que, sin embargo, nos explican la dimensión mítica e imaginaria con que los ciudadanos viven cotidianamente la política y la democracia. La Ciencia Política ha asumido programáticamente lo que no era sino un mandato normativo de la teoría liberal clásica: la esfera política como ámbito público de racionalización del poder (y, en consecuencia, de las instituciones correspondientes). Sin embargo, estas herramientas normativas, al excluir las dimensiones pasionales, míticas, imaginarias, espectaculares, simbólicas o dramáticas de la política, nos privan de conocer las corrientes subterráneas de los sistemas democráticos.

No podemos concluir este artículo sin citar algunos movimientos sociales orientados hacia la praxis política que han tomado al cine como arma y espacio de lucha. Nos referimos fundamentalmente al socialismo y al feminismo (si bien dentro de ellos existen notables diferencias e, incluso, divergencias). Podríamos haber incluido también el uso del cine por otros movimientos de minorías (cine gay, chicano, etc.) o de cinemas nacionales no occidentales.

52 RYAN, «The Politics of Film...», p. 477.

53 Véase Georges BALANDiER, El poder en escenas. De la representación del poder al poder de la representación, Barcelona, Paidós, 1994. 
Con ello no pretendemos hacer un estado de la cuestión sobre tan inabarcables asuntos, sino ilustrar someramente la praxis - y las controversias derivadas de tales experiencias- de los debates teóricos expuestos en los epígrafes precedentes.

\section{EL CINE COMO ARMA POLÍTICA}

Cuando hablamos del uso del cine como arma política no nos estamos refiriendo exclusivamente a la utilización propagandística de determinado tipo de filmes (documentales políticos, bélicos, etc.) ${ }^{54}$. Efectivamente, las más elaboradas prácticas políticas del cine se han orientado muy frecuentemente hacia la realización de análisis fílmicos (reveladores de la ideología dominante naturalizada en el cine comercial) o al cuestionamiento y alternativas a los modelos dominantes de representación cinematográfica (en cuanto reproductores de los modos de construir la realidad por parte de los grupos hegemónicos). Algunos movimientos políticos entienden el cine como un espacio cultural a través del cual cabe la intervención política en la sociedad. Por su tradición y solidez teórica y práctica, veremos a continuación la relación entre movimientos socialistas y feministas y el cine.

\subsection{Socialismo y cine: cine politico y militante}

El interés de los movimientos socialistas por el cine — como ya hemos anotado- no es algo nuevo: hunde sus raíces en las primeras décadas del siglo $\mathrm{XX}^{55}$. En esta primera época, el uso político del cine por las organizaciones obreras obedecía a criterios fundamentalmente contra-propagandísticos: la necesidad de combatir la propaganda burguesa creando un espacio propio de publicidad. Diversos colectivos dieron lugar a una ingente producción documental, sin que falten tampoco algunos filmes de ficción ${ }^{56}$. Desde el final de la II Guerra Mundial el uso propagandístico del cine ha sido poco sistemático, siendo mucho más común, por contra, la aparición de filmes comerciales de

${ }^{54}$ Sobre el uso propagandístico del cine pueden verse las continuas referencias al cine en Garth S. Jowett y Victoria O’Donnell, Propaganda and Persuasion, Londres, Sage, 1992. También, Alejandro PiZarroso Quintero, Historia de la propaganda. Notas para un estudio de la propaganda politica y de guerra, Madrid, Eudema, 1993. Para un caso muy peculiar de uso propagandístico del cine puede verse la epopeya ferroviaria de Alexander MEDVEDKIN, El cine como propaganda política. 294 días sobre ruedas, México, Siglo XXI, 1977.

${ }_{55}$ Para los antecedentes históricos y desarrollo del cine militante vid Andrés Linares, El cine militante, Madrid, Castellote, 1976.

56 Un ejemplo paradigmático es La marsellesa (1938), de Jean Renoir, financiada por subvención popular a instancias del colectivo Cine y libertad. También podríamos mencionar el cine político de ficción del bando republicano durante la guerra civil, como Aurora de esperanza (1936), de Antonio Sau, o Sierra de Teruel (1939), de André Malraux. 
orientación política crítica. Jowett y O’Donnell señalan cuatro causas de que en la actualidad el cine haya limitado su función propagandística expresa ${ }^{57}$ : 1) Preferencia por el filme de alto presupuesto; 2) Dificultad para la realización de documentales; 3) Oligopolio de la distribución; y, finalmente, 4) Uso del vídeo como aparato propagandístico. Parece evidente que en la medida en que la televisión sustituye al cine en algunas de sus funciones, la utilización de películas como instrumento político de resistencia se vuelve más infrecuente y -a la par- más sofisticada.

En una segunda época, sobre todo desde mediados de la década de los sesenta, a la praxis del cine de resistencia se añade una ingente reflexión teórica. Es el momento en que aparecen expresiones como "cámara ametralladora" o «usar la cámara como un fusil». No podemos entrar aquí en los complejos debates sobre política y cine que se desarrollaron en el hirviente magma de la izquierda de los años sesenta, debates y prácticas fílmicas que comienzan a decaer inexorablemente a partir de la segunda mitad de los años setenta ${ }^{58}$. Estas reflexiones en torno al cine obedecían a estrategias muy concretas de las fuerzas políticas en lucha dentro del seno de la propia izquierda europea y latinoamericana post-68. En Francia, el debate teórico político sobre el cine es ejemplar de tales divisiones ${ }^{59}$.

La línea sostenida por la revista Cinethique, en la que escribían Jean-Louis Baudry y Gérard Leblanc, entre otros, representa a la izquierda radical del «Front Rouge». Su ideología es claramente marxista-leninista — crítica con el PCF - y su apuesta cinematográfica es por el llamado cine materialista. Para Baudry y otros, el dispositivo representativo del cine (modos de representación, tipo de relación que establece con el espectador, etc.) es claramente reaccionario.

La Nouvelle Critique, cuyo máximo exponente es Jean-Patrick Lebel, adopta posiciones vinculadas al comunismo tradicional del PCF (acusado de revisionista por la extrema izquierda). Desde esta posición se rechaza el presupuesto de que las formas cinematográficas son ideológicas por sí mismas. Lebel pone el acento en la utilización histórica y concreta del cine, en la orientación ideológica que lo dirige en cada caso, y el lugar que ocupa en el proceso global de significación. Su apuesta fílmica es el cine político.

Cahiers du Cinéma, posiblemente la revista cinematográfica más prestigiosa, atraviesa varias etapas. En la época 1969-1972 se sitúa en una línea político-analítica intermedia entre Cinethique y las tesis del PCF de Lebel. En este período brilla la pluma de Jean-Louis Comolli. En la etapa 1972-1974 triunfa la línea marxista-leninista de orientación maoísta. En este período no hay

57 JOWETT y O’DONNELl, op. cit., pp. 90-101.

58 Estos debates quedan magníficamente compendiados y comentados en VV.AA.: Los años que conmovieron al cinema. Las rupturas del 68. También en Francesco CASETTI, Teorías del cine (Madrid, Cátedra, 1994), en especial en el capítulo XII, «Ideología, Política, Alternativas».

59 Vid. Santos ZunZUNEGUI, «El fondo del aire es rojo: cine/ideología/política en el entorno de mayo de 1968", en VV.AA.: Los años que conmovieron al cinema, pp. 143-159. 
fotos, no se firman los artículos y se escriben elaboraciones teóricas de altos vuelos. A partir de 1975 comienza la despolitización de la revista.

Hemos descrito brevemente el debate francés de principios de los años setenta porque nos remite a una división usual cuando se describe el uso político estratégico del cine y que conviene delimitar: cine militante y cine político.

El cine político surge al amparo de las convulsiones de los años sesenta, triunfando sobre todo en Francia e Italia en el período 1968-1975, al socaire de las estrategias reformistas de sus respectivos partidos comunistas. Este tipo de cine se caracteriza porque la política en sus manifestaciones más concretas (partidos, sindicatos, sistema judicial, etc.) es el referente directo de las tramas argumentales. Estas películas utilizan los más clásicos recursos del cine de género tradicional, particularmente la ficción policíaca o la indagación periodística. Su objetivo es claro: introducir un discurso crítico de denuncia -una pedagogía moralizante- en el seno de la industria capitalista del cine. Por consiguiente, no se cuestionan ni los modos de representación cinematográfica ni la relación espectador/filme (el espectador va a una sala normal, paga su entrada, asiste a un espectáculo entretenido, se identifica con los protagonistas, se indigna un poco por las injusticias mostradas, y luego se va a su casa). Estas películas, cuyo modelo más notorio es $Z$ (1968), de Constantin Costa-Gavras — con la colaboración en el guión de Jorge Semprún-, no dudan en recurrir a conocidos actores (vgr. Yves Montand, Irene Papas, Jean Louis Trintignant) con el objetivo de atraer a la mayor cantidad de público posible. Como es comprensible, estas estrategias culturales, paralelas a las estrategias puramente políticas de "frente democrático" de los partidos comunistas tradicionales, fueron duramente criticadas por la izquierda extraparlamentaria. La defensa teórica de la práctica del cine político la realizó brillantemente Lebel en los textos recogidos en su obra de referencia Cine e ideología $a^{60}$.

El cine militante es una denominación que abarca un buen número de corrientes activistas. Pese a esta variedad, el cine militante posee unos rasgos comunes: prestar atención al análisis de problemas que afectan a las clases trabajadoras, medir su valor por su eficacia concienciadora y transformadora de la realidad, ofrecer al espectador un papel activo en la experiencia cinematográfica y, finalmente, considerar que el lenguaje fílmico tradicional es algo ideológico en la medida en que contribuye a dotar de sentido a la realidad ${ }^{61}$. Una dis-

${ }^{60}$ Jean-Patrick Lebel, Cine e ideología, Buenos Aires, Granica, 1973. Más allá del concreto contexto histórico del debate francés en que se sitúa este libro, con el paso de los años las reflexiones de Lebel han envejecido con cierta dignidad. En una línea parecida pero mucho menos brillante se sitúa la obra de Raúl BeceYro, Cine y politica, Caracas, Dirección General de Cultura de la Gobernación del Distrito Federal, 1976.

${ }^{61}$ En 1968 se constituyen los llamados Estados Generales del Cinema Francés, que reúnen a la casi totalidad de los profesionales de la industria del cine. Estos Estados Generales fueron controlados pronto por los grupos más radicales de izquierda (lo que provocó el abandono de la mayoría de los participantes, dicho sea de paso), que los utilizaron como instrumento de su estrategia revolucionaria. En el Manifiesto por un cine militante, los Estados Generales exponen claramente los objetivos de este tipo de cine: 
tinción muy clara entre cine político y militante la ofrece la declaración de principios de Jean-Luc Godard titulada (al modo de Lenin) ¿Qué hacer?, de enero de $1970^{62}$. Este tipo de cine militante cristalizó en la formación de colectivos obreros que rodaban sus propios filmes en las fábricas en que trabajaban, denunciando problemas concretos y participando activamente en los debates planteados tras la proyección. Ejemplos de estos colectivos fueron los grupos franceses SLON, Medvedkin o Dziga Vertov (en alguno de los cuales estuvo Godard cuando abandonó el cine de autor), o el italiano Collettivo Cinema Militante, entre otros. Igualmente, los cineastas militantes trataron de establecer canales alternativos para la exhibición y distribución de estas películas, al margen de los cauces normales del cine industrial capitalista.

La preocupación teórica por deconstruir las formas burguesas de representación cinematográfica, dio lugar a la práctica fílmica del cine materialista y, a veces, más específicamente, del autodenominado cine estructuralista. Este tipo de filmes militantes pretendían subvertir el discurso idealista sobre el cine poniendo de manifiesto el propio proceso de elaboración de la película, es decir, creando un distanciamiento brechtiano que impida el mecanismo ideológico de la proyección-identificación y que deje ver el carácter material de la película como producto (sonido directo, facturas de compra del material, voces en off de los miembros del equipo, etc.). Se va, por tanto, en contra de la idealista transparencia enunciativa del cine clásico y de la ideología del espectáculo ${ }^{63}$.

Sin embargo, según se van enfriando los rescoldos de mayo de 1968, el cine militante va languideciendo hasta prácticamente desaparecer, al menos en Occidente. Los motivos del eclipse del cine militante son varios: de manera general, a causa de la disminución de la legitimidad social de los discursos revolucionarios en Europa, lo que hizo cada vez más ineficaces y difíciles los filmes de agitación (rodaje de huelgas, manifestaciones, cargas policiales, etc.);

«1) La utilización del cine como arma de lucha política (...) y sobre el que los militantes implicados ejercen control político tanto en su realización como en su distribución.

2) La utilización del cine como base de intercambios de experiencias políticas; de ahí deriva la necesidad de suscitar tras cada proyección cualesquiera debates que puedan desencadenarse a consecuencia de los problemas concretos que la originaron. Este método permite a los trabajadores orientar otras realizaciones según las necesidades de su lucha y permitir la inclusión en aquéllas de las soluciones propuestas.

3) La utilización y la realización de filmes vinculados a acciones políticas (mítines, manifestaciones, huelgas, etc.).

4) Paralelamente a la difusión de tales películas, una información que las amplíe, las complete o las provoque.»

Citamos por la versión recogida en VV.AA.: Los años que conmovieron al cinema, p. 256.

${ }_{62}$ Este manifiesto militante se encuentra recogido en LINARES, op. cit., pp. 63-65.

63 Además de la antología de textos y manifiestos recogidos en VV.AA.: Los años que conmovieron al cinema, puede verse para una interesante reflexión sobre el cine materialista el libro de Christian Zimmer, Cine y política, pp. 253-281. 
en un nivel más concreto, fue la propia deconstrucción y transgresión de los modos de representación tradicionales del cine —axioma incuestionable del más elaborado cinema militante- lo que elevó al cine militante a los altares del elitismo cultural que tanto denostaban. Zunzunegui plantea certeramente esta contradicción: "¿Cómo compaginar las rupturas formales, las transgresiones a nivel del significante, la búsqueda de una nueva "forma" con la necesidad de llegar a un público formado en la frecuentación de obras típicas del modelo representativo industrial? Digámoslo rápidamente, esta contradicción nunca superada adecuadamente se encuentra en el eje del fracaso de múltiples intentos del cine militante. Cuanto más avanzada era la deconstrucción a que un filme se entregaba, mayor era su alejamiento de lo que se denominaba las amplias masas»" ${ }^{64}$.

La deconstrucción militante pretendía ser la "vanguardia roja», en oposición a la "vanguardia blanca» cuya deconstrucción formalista no obedecía a estrategias políticas revolucionarias sino a la depuración modernista del arte. Sin embargo, finalmente ambas posturas devinieron elitismo cultural para consumo de iniciados. La vigencia actual del cine militante es, en consonancia con los nuevos tiempos, casi inexistente. Sólo algunas experiencias del tercer mundo, los movimientos de radios libres o el uso militante del vídeo, mantienen en cierta forma la llama activista en el audiovisual ${ }^{65}$. Por contra, el cine político - fuera de su contexto original y asimilado al filme de denuncia- sigue apareciendo de vez en cuando en las pantallas. Desde posiciones liberales, directores como Oliver Stone (Salvador, JFK) o Jim Sheridan (En el nombre del padre) han alcanzado importantes éxitos comerciales, siendo incluso recompensados con Oscars de Hollywood (lo que prueba su inocuidad política, podría argumentarse maliciosamente). Al calor de las reformas neoliberales de las últimas décadas ha resurgido un tipo de películas críticas centradas en las condiciones de las clases trabajadoras e inmigrantes; destacando el éxito internacional de autores británicos como Ken Loach — con películas como Riff Raff (1990), Lloviendo piedras (1993), Ladybird, Ladybird (1994) o La canción de Carla (1996) - o Stephen Frears (Café irlandés, 1993).

\subsection{Feminismo y cine}

La relación entre los movimientos feministas y el cine es la crónica de un encuentro ineludible. Hay que partir de la base de que el feminismo, como actividad y análisis político, ofrece una extensa gama evolutiva de enfoques y

${ }^{64}$ Santos ZunZunEGui, «El fondo del aire es rojo...», pp. 154-155.

${ }^{65}$ Para una breve panorámica hasta mediados de los años ochenta véase John DownING, Radical Media. The Political Experience of Alternative Communication, South End Press, 1984. En 2000 ha publicado Radical Media: Rebellious Communication and Social Movements. 
posturas. De hecho - y desde la perspectiva que aquí nos interesa-, las teorías feministas se encuentran atravesadas transversalmente por el marxismo, el psicoanálisis, la semiología o la más actual teoría política (Benhabib, Cornell). Sin embargo, pese a esta heterogeneidad y variedad hay un presupuesto común que nos interesa sobremanera: lo cultural (imágenes, representaciones, etc.) como campo fundamental para el análisis y la intervención feminista. Como señala Annette Khun, una de las mayores contribuciones teóricas del movimiento feminista ha sido su insistencia en el valor significativo de los productos culturales, en especial cuando adoptan la forma de representaciones socialmente dominantes sobre las mujeres y a causa del carácter ideológico de tales representaciones, al constituir la categoría «mujer» y al delimitar y definir el denominado «sistema sexo/género» ${ }^{66}$.

De esta manera, concebir el campo de las representaciones e imaginarios culturales como un ámbito fundamental de generación/reproducción de la estructura sexista de las sociedades — más allá de los debates marxistas sobre las condiciones económicas y la autonomía relativa de lo cultural—ofrece al feminismo un campo abonado para interesarse por el cine. Este interés por el cine no puede ser más que político, en la medida en que tiene como objetivo intervenir transformativamente en la sociedad a través de la cultura.

La labor feminista en el mundo del cine se ha desarrollado a través de dos prácticas que, si bien conceptualmente parecen claramente distintas, en la práctica ofrecen límites difusos: el análisis feminista del cine dominante y la realización de un cine de mujeres.

La crítica y análisis teórico feminista del cine dominante, en particular del cine clásico de Hollywood, se nos ofrece como una práctica política en la medida en que pone de manifiesto la construcción ideológicamente interesada del concepto mujer a través de su representación cultural ofrecida como natural y mediante la construcción de un espectador implícito en el texto fílmico construido sobre la base de la mirada y el deseo masculino.

Uno de los más conocidos escritos feministas sobre el cine es el ya clásico «Visual Pleasure and Narrative Cinema» (1975), de Laura Mulvey. Este texto feminista de orientación psicoanalítica expone en sus primeras líneas los objetivos teóricos que persigue: «Este artículo intenta usar el psicoanálisis para descubrir dónde y cómo la fascinación del cine es reforzada por pautas preexistentes de fascinación que ya operan dentro del individuo y de las formaciones sociales que lo han moldeado. El artículo toma como punto de partida la forma en que el cine refleja, revela e incluso actúa en la rígida y socialmente establecida interpretación de la diferencia sexual; interpretación que controla las imágenes, las formas eróticas de mirar y el espectáculo. Esto es útil para comprender lo que ha sido el cine, cómo su magia ha operado en el pasado, a la vez que intenta una teoría y una práctica que cambiará el cine del pasado. La teoría psicoanalítica es usada aquí como un arma política, demostrando la

${ }^{66}$ Annette Khun, Cine de mujeres. Feminismo y cine, Madrid, Cátedra, 1991, p. 18. 
manera en que el inconsciente de la sociedad patriarcal ha estructurado la forma fílmica ${ }^{67}$.

Los análisis feministas han cimentado una fresca e innovadora corriente de análisis en las últimas tres décadas. La crítica feminista, al carecer de una técnica específica de análisis fílmico, ha usado las herramientas conceptuales de metodologías desarrolladas fuera del pensamiento feminista (sociología, semiótica, psicoanálisis, etc.). El punto de unión de tales analistas es la perspectiva y la estrategia con que utilizan dichas metodologías ${ }^{68}$.

Los primeros análisis realizados por feministas adoptaron un enfoque sociológico empírico interesado por describir la manera en que las mujeres eran representadas en el cine clásico de Hollywood. La infrarrepresentación y estereotipación en las películas —el clásico molde de virgen/puta— obedecía claramente al discurso patriarcal y a su forma de representar a las mujeres. Hay tres libros que son considerados decisivos en la emergencia de la teoría feminista del cine: Popcorn Venus: Women, Movies and American Dream (1973), de Marjorie Rosen; Women and Their Sexuality in the New Film (1974), de Joan Mellen, y From Reverence to Rape: The Treatment of Women in the Movies (1975), de Molly Haskell. En sus análisis escogían normalmente películas del cine clásico de Hollywood, más frecuentemente aquellas dirigidas por mujeres o en las que las mujeres desempeñaban el papel principal. De esta manera, pretendían analizar comparativamente la diferencia entre la mirada masculina y la femenina a la hora de construir la narración. Más recientemente, los análisis se centran en cine dirigido por mujeres, principalmente directoras ajenas a Hollywood, con la intención de hacer un crítica reflexiva sobre la posibilidad de elaborar un cine feminista o, al menos, realizado desde la mirada femenina.

Esta incipiente teoría y crítica fílmica feminista pronto se vio desplazada por una nueva orientación fuertemente influida por el psicoanálisis y los métodos semióticos de análisis de la imagen. Desde este punto de vista - sustentado en revistas como Camera Obscura y en algunos artículos de Screen-, el objetivo era analizar cómo el texto fílmico construye a su propio espectador cinematográfico implícito a través de la pulsión de ver y movilizando el deseo masculino. Laura Mulvey ha sido probablemente la teórica feminista en este enfoque más influyente y citada desde la publicación de su seminal artículo en 1975. No obstante, a la influencia del psicoanálisis lacaniano se sumó a mediados de los años ochenta la recepción del pensamiento de Foucault y su aplicación a la crítica feminista por autoras como Teresa de Lauretis y su notable Technologies of Gender: Essays on Theory, Film and Fiction (1989).

En la década de los noventa la teoría fílmica feminista ha visto cómo sus intereses se multiplicaban y, hasta cierto punto, se convertían en campo acadé-

${ }^{67}$ El seminal artículo de Mulvey se publicó en Screen, vol. 16, núm. 3, 1975. Citamos por la versión recogida en NichOLS (ed.): Movies and Methods, vol. 2, Los Ángeles, University of California Press, 1986, pp. 305-315.

${ }_{68}$ Para estos problemas epistemológicos, vid KUHN, op. cit., pp. 84 y ss. 
mico más que en estrategia política. En Estados Unidos, muchos enfoques feministas rápidamente han sido asumidos en los ámbitos universitarios por la vía de los llamados Gender Studies, asumiendo en parte las aportaciones más comprensibles del post-estructuralismo. En el Reino Unido, por contra, los análisis feministas se mueven en ámbitos menos institucionales.

Al amparo de la expansión de los Estudios Culturales, se han desarrollado recientemente nuevos campos de investigación como los análisis empíricos de la recepción o los hábitos de consumo cultural, en consonancia con el giro culturalista hacia el empirical reader que ya hemos citado. Las analistas de la recepción señalan que es necesario enlazar la experiencia vital de las espectadoras y la forma en que éstas pueden dotar de sentido a una película en concreto. Como ha señalado Jennifer Hammet, en oposición a ciertas teóricas postestructuralistas de referencia, los mecanismos de representación fílmica en sí mismos no son un problema para las feministas. El problema no es epistemológico - como sostiene una parte de la Teoría Fílmica feminista—, sino la capacidad para ofrecer respuestas a los textos fílmicos patriarcales generando películas feministas ${ }^{69}$.

Esta última idea nos lleva a la otra gran práctica fílmica feminista: la realización de películas feministas, o al menos, realizadas desde una mirada femenina. Todas estas propuestas cobran fuerza a principios de los años setenta, recogiendo el impulso de la denominada «segunda ola» del feminismo contemporáneo. Esta pretensión de realizar un cine feminista ${ }^{70}$ — que sería paralela a la del ya comentado cine militante- presupone por lo general un elevado grado de deconstrucción y subversión de los mecanismos del cine clásico, tanto en el aspecto textual como en el de la experiencia cinematográfica (espectador activo, debates, etc.). Un ejemplo de ello serían películas como Nathalie Granger (1972), de Marguerite Duras, o incluso el filme dirigido por la propia Laura Mulvey, Riddles of the Sphinx (1976). Paralelamente a estas obras teóricas básicas se habían sucedido una serie de documentales y festivales de cine de mujeres (vgr. Nueva York, Chicago, Toronto), así como publicaciones periódicas especializadas como Women \& Film o Camera Obscura ${ }^{71}$. Intentar construir un cine feminista presupone el interés por crear ámbitos propios, espacios públicos alternativos al espacio de representación dominante. Sin embargo, esta vocación minoritaria no ha impedido la aparición de largometrajes comerciales con discursos feministas como Las hermanas alemanas (1981), de Margarethe Von Trotta, o la holandesa Antonia (1995), de Marleen Gorris.

${ }^{69}$ Jennifer HAMmET, «The Ideological Impediment: Epistemology, Feminism and Film Theory"», en Richard AlLen y Murray SMITH (eds.): Film Theory and Philosophy, Oxford, Clarendon Press, 1997, p. 257.

${ }_{70}$ Nos remitimos para este debate a KUHN, op. cit., pp. 145 y ss.

${ }^{71}$ Véase E. Ann Kaplan, Las mujeres y el cine. A ambos lados de la cámara, Madrid, Cátedra, 1998. 


\begin{abstract}
Popular culture is probably one of the strangest and most significant phenomena of the $20^{\text {th }}$ century, and one which has been the least studied from the viewpoint of political science. In the first place, this article places particular stress on the reasons that may have motivated this lack of interest, in terms of political science, in popular culture in general, and specifically in the cinema, one of its most obvious exponents. Secondly, we report on the way in which over the last fifteen years the discipline of political communication has, moving beyond the dominant paradigm of voter persuasion, opened up to the study of discourses based on fiction and entertainment. The third and final section is devoted to a short analysis of how the cinema is used by some social movements as a weapon and a place where political response can occur, and this is where we home in on the relationships existing between socialism, feminism and the cinema. We consider that the political-scientific study of public discourses which recreate collective identities and construct the political worlds of all citizens is a productive study field. The growing expansion of focusses placed on the theory of discourse and Cultural Studies in political science seem to confirm this academic liberalization.
\end{abstract}

